\title{
TIDAL CURRENT ENERGY AN OVERVIEW
}

\author{
T.S. Desmukh ${ }^{1}$, Amitkumar S. Gawas ${ }^{2}$ \\ ${ }^{1}$ Professor, Department of civil engineering, M.A.N.I.T., M.P., India \\ ${ }^{2}$ M. Tech Scholar, Department of civil engineering, M.A.N.I.T., M.P., India
}

\begin{abstract}
Ocean currents are an enormous source of green energy. This energy from marine currents can be extracted by means of tidal turbines. This paper explains different types of tidal current turbines. This paper discusses about tidal energy and site selection criteria for tidal current turbine in general. This paper gives general overview about tidal current turbine design methods such as the blade element momentum theory and computational fluid dynamics.
\end{abstract}

Keywords: Tidal energy, Tidal current turbines, Site selection, BEMT, CFD

\section{INTRODUCTION}

Energy is the important driving force of world economy. Most of the developing countries and industries are still totally relying on the conventional energy resources that are coal, oil and gas. Conventional energy resources will vanish within few decades because of its limited availability. Excessive uses of conventional energy resources are harmful for health of living things, environment and ozone layer. Clean renewable energy is the best alternative to avoid further deterioration of the earth's environment. This can be possible only when there is solution of many technical problems. All countries are individually or collectively taking efforts to solve technical problems and developing new technologies in the field of renewable energy.

Hydro power, Wind, Solar and Ocean energy are some of the most common sources of clean renewable energies. Hydro power energy is one of the first harnessed clean sources of energy and hence has considerable development over the years. Hydro power is stored in the form of potential energy by building dams across the river. This potential energy is converted in to kinetic energy by turbines which are finally converted to electrical energy with the help of generators. To get land for building dams and storage reservoir is big environmental and people rehabilitation issue in most of the countries. Next comes the wind energy. Wind energy is an intermittent source of small magnitudes. The research for improving the efficiency of wind turbine is still under progress. Solar energy is the most abundant source of available energy. Solar cells are used to convert solar energy to electricity. The main issue with solar energy is that the solar cells are very costly and hence cannot be used for mass production. Latest addition in the field of renewable energy is the energy from oceans. Ocean possess many forms of energy namely - Thermal energy, tidal energy, and energy from waves and circulating currents. The main focus of this paper is tidal current energy. Research is still underway for developing devices to harness the vast potential of tidal current energy possessed by ocean. In this paper an attempt has been made to discuss the current scenario for tidal energy.

\section{TIDAL ENERGY}

The relative motion of earth and moon causes a change in the gravitational field which results in the formation of tides. The magnitude of tides depends upon the positions of the moon and the sun relative to the earth, shape of the coastline, sea floor and the rotation of the earth. Other than gravitational pull some other causes of tidal currents are coriolis forces created due to earth's rotation and density differences due to temperature and salinity variation.

Tidal energy can be utilized mainly in three forms Potential energy, wave energy and tidal current energy. Tidal barrages have been used for many years to utilize tidal energy in the form of potential energy to generate electrical energy with the help of turbines as shown in schematic diagram of tidal barrages in Fig.1. There are two types of tidal barrages single basin tidal barrages and double basin tidal barrages.

Single basin scheme has one basin and it is created by constructing barrages across the estuary. This scheme has three methods to generate electricity by considering the fall of tides or the rise of tides or both rise and fall of tides. In first method when tide is rising sluice gates are opened and water is allowed to store in to the basin. At beginning of the ebbing when sufficient hydrostatic head is achieved between low sea level and stored water level then sluice gates are closed. Once the sea is at its low level after fall of tide then water is allowed to pass through the turbine and generate electricity. When the desired level of hydrostatic head is fall then sluice gates are opened to drain the stored water and maintain same level between stored water and sea water. In this method pump can be used to store water in to the basin when demand of electricity is less.

In second method sluice gates are kept closed during flood and water is passed through turbine and generates electricity. When tides start falling and the desired level of hydrostatic head between sea level and flood level is less at that time turbine stops generation of electricity and sluice gates are opened to achieve the same sea level at both side of barrage quickly. 
Third method generates power during both the flood and ebb tides. The direction of flow through the turbines is opposite during the flood and ebb tides. Hence the machine used for power generation can act as a turbine for both direction of flow. During ebb tide sluice gates are closed when tide level and basin level is same. When the sea level falls and required minimum head for turbine is reached then the turbine operates to generate power by emptying the reservoir. When available minimum head to operate turbine is utilized then the sluice gates are opened and equalized the level of reservoir with the sea level during flood tide. After equalizing the level sluice gates are closed and flow is allowed to pass through turbine to fill the basin and hence turbine generates power during the flood tide. Just before the end of flood tide turbine shut down and sluice gates are opened to fill the basin quickly.

Double basin scheme has two basins. Main basin is used to operate similar to that of the single basin operating with ebb motion as explained earlier. During this type of electricity generation small portion of electricity is used to pump water in to second basin. This will fulfill fluctuating energy demand.

There are very less sites available for tidal barrages because it can be built only across natural estuary. La Rance power facility in France is the largest operating tidal power plant. Its capacity of power generation is about 240MW. Another tidal power plant facilities are - Annapolis tidal generation at Bay of Fundy, Canada (20MW); Kislaya Guba power plant facility in Russia (400KW); Jangxia Creek at east China sea $(500 \mathrm{KW})$.

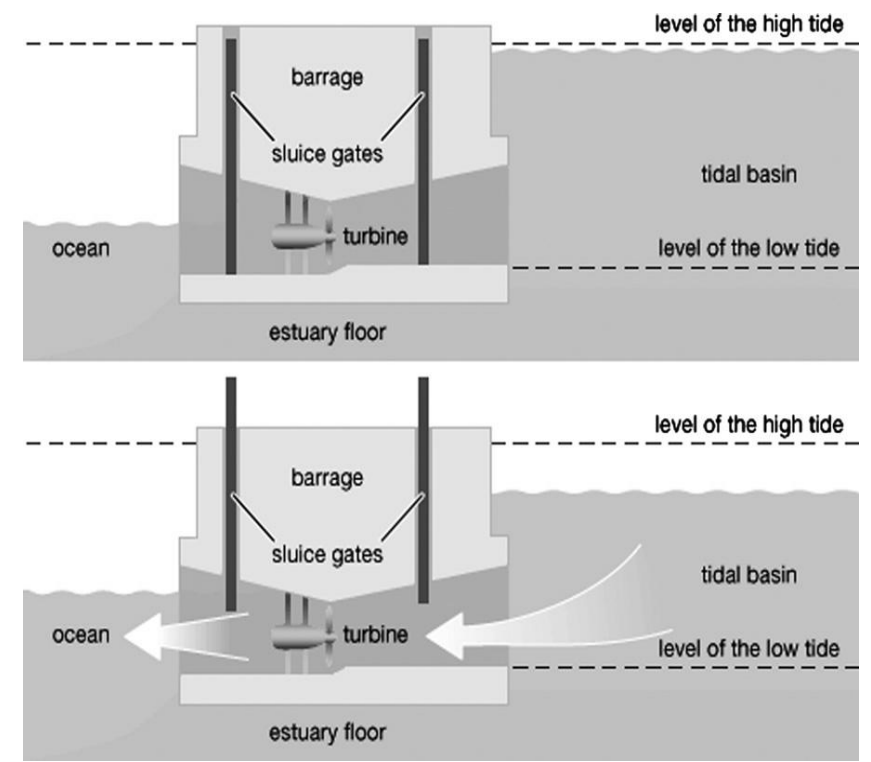

Fig -1: Schematic diagram of tidal barrage [7]

Another form of ocean energy is wave energy. When wind passes over the sea surface then waves are generated. These waves can be utilized to generate electricity by using specially designed devices which can convert wave energy in to mechanical energy and finally in to electrical energy. There are mainly four type of devices are in use to convert wave energy in to electrical energy that are - overtopping devices, point absorbers, attenuators and terminators. However the technology to utilize wave energy is in developing stage.

Third form of tidal energy is Tidal current energy which is the form of kinetic energy which can be utilized by tidal current turbines to generate electricity through generator.

One study estimated that India has about 8000 MW potential of tidal energy. Gujarat state of India has tidal energy potential of $7000 \mathrm{MW}$ in the Gulf of Cambay and $1200 \mathrm{MW}$ in Gulf of kutch. West Bengal state of India has tidal energy potential of $100 \mathrm{MW}$ in the Gangetic Delta in Sunderbans region. Gujarat power corporation Ltd. Govt. of Gujarat and M/S Atlantis Resource Corporation (U.K.) had signed on MoU for commissioning of 50MW Tidal power project [16].

\section{SITE SELECTION}

To select best site designer should study physics of tides, topology of seabed, Temperature, salinity and $\mathrm{pH}$ level, environmental importance of sites and socio-economic value of site.

The study of physics of tides mainly includes current velocity and wave patterns of the tides. While selecting a site it should be kept in mind that high current velocities (2 $\mathrm{m} / \mathrm{sec} \&$ above) should be available for major period of the year at the site; so as to ensure sufficient energy production throughout the year. Low velocity current $(1.2 \mathrm{~m} / \mathrm{s}$ to $2 \mathrm{~m} / \mathrm{s})$ can also be utilized if these current are available continuously like river current flows.

Available power in tidal current is -

$$
P=\frac{1}{2} \rho A V^{3}
$$

Where $\mathrm{P}$ is power, $\rho$ is density of sea water, $\mathrm{V}$ is the current velocity and $A$ is the swept area of the rotor.

Sites which have high environmental importance such as reserved sanctuary, fishing zones, area reserved for endangered sea species should be avoided because construction and installation of turbines may cause environmental damage. Also the rotation of rotor and turbulence created by rotation may disturb the biological cycle of any sea species. Selected site must not be in the vicinity of any busy sea route of ship. Else ship activity may create hurdles for installation, operation and maintenance of tidal current turbines.

Topology of seabed is also an important factor from turbine installation point of view. If seabed topology has large plane surface area then a number of tidal current turbines can be installed similar to the wind turbine farm.

Salinity, temperature and $\mathrm{pH}$ level also need to be kept in mind while selecting a site as they affect the cavitation characteristic of the turbine rotor blade. If the temperature, salinity and $\mathrm{pH}$ level are high at particular site then the 
chances of cavitation on the blade and corrosion rate of rotor and its structure is also high. Hence to avoid corrosion surface coating of very high quality is required. If the surface finish of turbine blades is very smooth then cavitation can also be avoided.

The selected site should be nearer to the land, so that the erection cost of electrical transmission lines from turbine to the grid and maintenance cost of the electrical transmission lines is minimized.

\section{TIDAL CURRENT TURBINE}

Tidal current turbines are devices which convert kinetic energy of tidal currents in to mechanical energy and finally generate electricity. These turbines are designed in such a way that it can generate electricity during both flood current and ebb current.

Tidal current turbines can be classified according to the direction of flow of tidal current passing over the turbine are as i) Horizontal axis tidal current turbine (HATCT) ii) Vertical axis tidal current turbine(VATCT).

\subsection{HATCT}

In this type of tidal current turbine tidal currents flow parallel to the axis of rotation of the rotor. HATCT rotates due to lift force generated by the airfoil section of the blade when tidal currents pass over the rotor. Fig. 2 explains the working principle of HATCT.

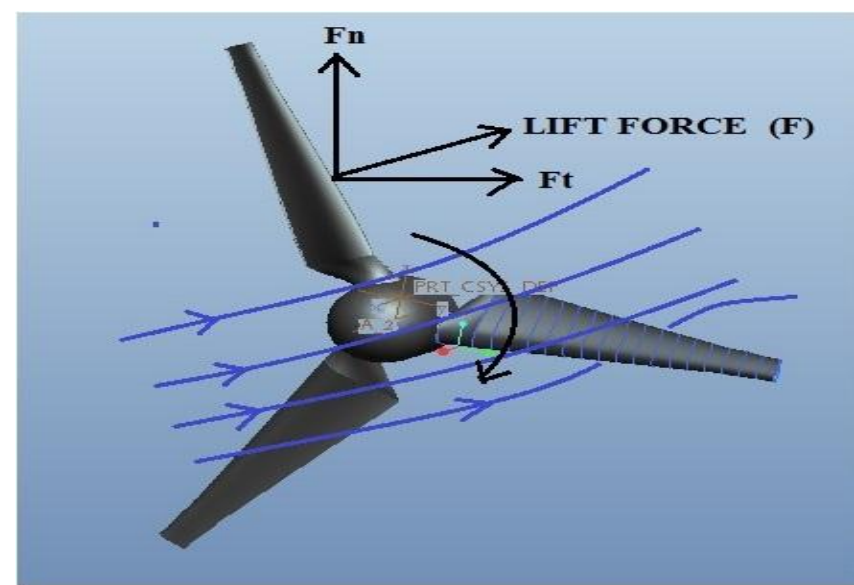

Fig -2: Schematic diagram to explain working principle of HATCT

Rotor of a HATCT has 2 or 3 blades. Mostly 3 blade rotor design is used because of its structural stability. The blades are connected to the hub. Hub is connected to the shaft and the shaft is finally connected to the gearbox and generator assembly. Gearbox and generator are placed at the rear end of the hub of the HATCT.

This whole assembly is then installed on a base structure. The type of base structure to be used depends upon seabed topology and depth of seawater at the site. If the selected site has shallow water depth then gravity base, monopole and piled jacket is used as base structure of the HATCT. If the water depth is large then floating type of structure can be used to support the tidal current turbine rotor assembly. In floating type structure rotor assembly is installed below the floating platform and this platform is connected by a chain to the seabed.

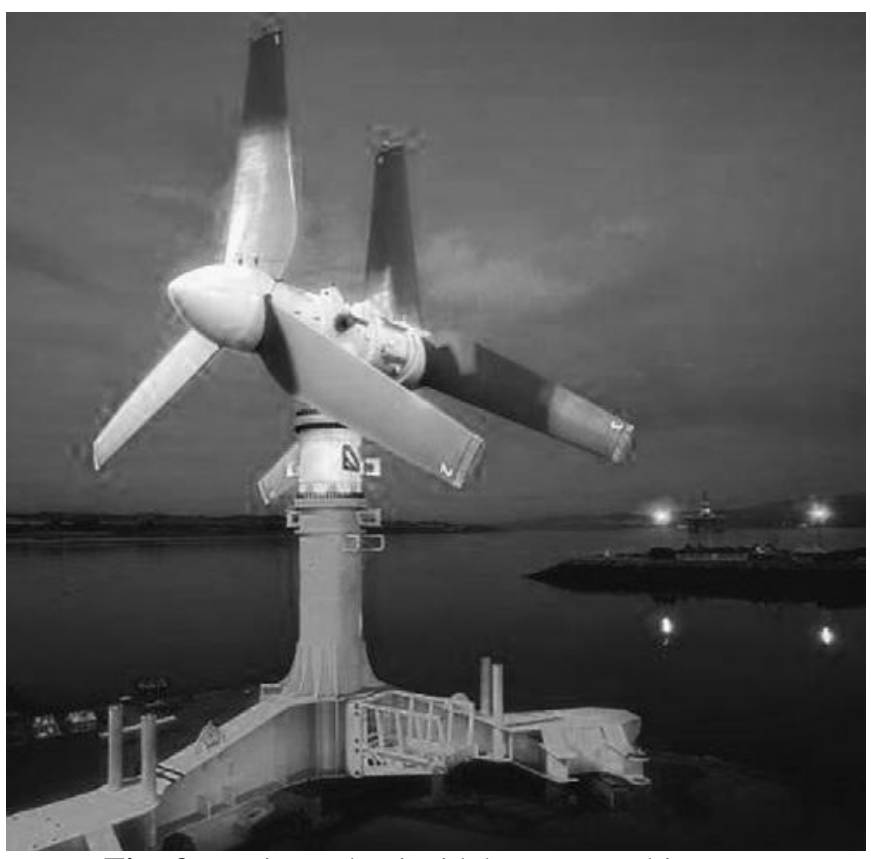

Fig -3: Horizontal axis tidal current turbine [7]

Horizontal axis tidal current turbine has a simple design and it is easy to manufacture as the rotor shape is not complex. The rotor speed is very low hence it does not harm the marine life. The turbine rotor can be lifted above sea water hence its maintenance can be done easily as compared to a vertical axis tidal current turbine.

The main disadvantage of such turbines is that - due to the horizontal axis of rotation shaft output cannot be transferred above sea water on floating platform and hence the gearbox and generator have to be accommodated in the limited space behind the hub.

\subsection{VATCT}

Vertical axis tidal current turbines have a vertical axis of rotation vertical perpendicular to the flow of tidal currents. They are also called as cross flow turbines because the flow of tidal currents crosses through the turbine rotor.

Some of the common types of the vertical axis tidal current turbines are Squirrel cage Darrieus, H-Darrieus, Darrieus, Gorlov, Savonius (Fig.4) are the vertical axis tidal current turbines. Squirrel cage Darrieus turbine has vertical blades fixed between two circular plates. Gorlov turbine blades has helical shaped blades fixed between two horizontal circular plates, Whereas Savonius turbine blade is made up of two semi cylinder fixed along their length to the rotor axis, at $180^{\circ}$ to each other and with their curvature in opposite directions. These blades are fixed between 2 horizontal circular plates. H-Darrieus and Darrieus turbine blades are separately connected to the single axis as shown in fig.4. 
Darrieus type of tidal current turbine is lift driven turbine i.e. rotation of this turbine is due to lift force of airfoil of the blade when tidal current flows around the blades. Whereas Savonius type of tidal current turbine is rotated due to drag force created by the blade in tidal currents.

The main advantage of the vertical axis tidal current turbine is that the shaft power can be vertically transmitted over the sea surface which can be connected to the gearbox and generator. The gearbox and generator can be kept on a floating platform or vessel [1].

However due to the complex nature of its rotor and its weight the vertical axis turbines are more costly as compared to a horizontal axis tidal current turbine. Moreover due to the nature of flow through the turbine rotor these turbines are more prone to cavitation as compared to horizontal axis tidal current turbine. It is not a self-starting machine; it needs to be driven up.

\section{TIDAL CURRENT TURBINE DESIGN CONSIDERATION}

Designing methods and technologies used for tidal current turbines are similar to that of wind turbine designing methods and technologies. However there are lots of differences in design considerations; major differences are density and Reynolds number of flowing fluid and cavitation. The fluid flowing around tidal current turbine is sea water which is about 800 times denser than air. There is no cavitation problem in wind turbines whereas in tidal current turbine due to the high density flowing fluid there is cavitation problem.

Blade element momentum theory (BEMT) and computational fluid dynamics (CFD) are two main approaches for numerically analyzing the performance of HATCT [10]. BEMT comprises of two theories that are momentum theory and blade element theory.

Momentum theory includes a control volume analysis of the forces at the blade. This analysis is based on the conservation of linear and angular momentum. Blade element theory includes an analysis of forces at a section of the blade and these forces depend on blade geometry. The outcome of these two theories is combined and used in BEMT for performance analysis of HATCT.

CFD is used as a tool to analyze the flowing fluid around the rotor 3 dimensionally. CFD analysis can predict the performance of tidal current turbine. It shows pictorial view of pressure and velocity variation over surface of the blade. It is also used to predict the cavitation (i.e. local pressure on the surface of the blade falls below the vapor pressure of flowing fluid) inception on the surface of blade of tidal current turbine.

\section{CONCLUSION}

With the machine demand of energy and fast depletion of fossil fuels there is necessity to explore the renewable source of energy. Tidal energy is promising, predictable and very clean source of energy. There is abundance of potential sites which need to be explored world over for setting up of tidal current turbines. The basic design of HATCT is similar to that of wind turbines while that of vertical axis turbines is similar to cross flow hydraulic turbines. However due to their location on seabed their construction becomes different. Due to the difference in the working environment as well as flowing fluid there is a need for much research for improving the design of tidal current turbine.

\section{REFERENCES}

[1]. P L Fraenkel; Power from marine currents. Proc Instn Mech Engrs Vol 216 Part A: J Power and Energy (2002).

[2]. Mazharul Islam, David S.-K. Ting, Amir Fartaj. Aerodynamic models for Darrieus-type straight-bladed vertical axis wind turbines. Renewable and Sustainable Energy Reviews 12 (2008) 1087-1109.

[3]. J. F. Manwell, J. G. McGowan, A. L. Rogers. Wind Energy Explained Theory, Design and Application Second Edition;Wiley publication, 2009.

[4]. L. Wang, X. Tang, X. Liu .Conference: Wind Energy: Materials, Engineering and Policies (WEMEP), At India.

[5]. L.I. Lago, F.L. Ponta , L. Chen;Advances and trends in hydrokinetic turbine systems. Energy for Sustainable Development 14 (2010) 287-296.

[6]. AbuBakr S. Bahaj;Generating electricity from the oceans. Renewable and Sustainable Energy Reviews 15 (2011) 3399- 3416.

[7]. Haydar FaezHassan n, AhmedEl Shafie,Othman A.Karim. Tidal current turbines glance at the past and look into future prospects in Malaysia; Renewable and Sustainable Energy Reviews 16 (2012), 5707-5717.

[8]. Chul hee Jo, Jin young Yim, Kang hee Lee, Yu ho Rho;Performance of horizontal axis tidal current turbine by blade configuration. Renewable Energy 42 (2012) 195-206.

[9]. M. Rafiuddin Ahmed;Blade sections for wind turbine and tidal current turbine applications - current status and future challenges. Int. J. Energy Res. 2012; 36:829-844.

[10]. Ju Hyun Lee, Sunho Park, Dong Hwan Kim, Shin Hyung Rhee, Moon-Chan Kim; Computational methods for performance analysis of horizontal axis tidal stream turbines. Applied Energy 98 (2012) 512-523.

[11]. Baigong Wu, Xueming Zhang, Jianmei Chen, Mingqi $\mathrm{Xu}$, Shuangxin Li, Guangzhe Li; Design of high-efficient and universally applicable blades of tidal Stream turbine. Energy 60 (2013) 187-194.

[12]. Feng-Zhu Tai, Ki-Weon Kang, Mi-Hye Jang, YoungJin Woo, Jang-Ho Lee,. Study on the analysis method for the vertical-axis wind turbines having Darrieus Blades. Renewable Energy 54 (2013) 26-31.

[13]. Jai N. Goundar, M. Rafiuddin Ahmed.Design of a horizontal axis tidal current turbine. Applied Energy 111 (2013) 161-174. 
[14]. Ahmad Safwan Sakmani, Wei-HaurLam, Roslan Hashim, Heap-Yih Chong; Site selection for tidal turbine installation in the Strait of Malacca. Renewable and Sustainable Energy Reviews 21(2013)590-602

[15]. Ali Al-Abadi,Ozg ur Ertun, Florian Beyer, \& Antonio Delgado;Torque-Matched Aerodynamic Shape Optimization of HAWT Rotor. Journal of Physics: Conference Series 555 (2014) 012003.

[16]. http://pib.nic.in/newsite/erelease.aspx?relid=70685

\section{BIOGRAPHIES}

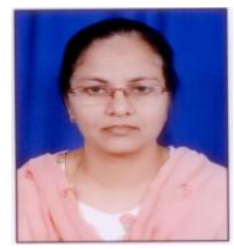

Specialization in Hydro Power, Water Resoures, CFD. Life member of following bodies: ISTE; Institution of Engineers; National Society for Fluid Mechanics and Fluid Power; Indian Association of Hydrologists

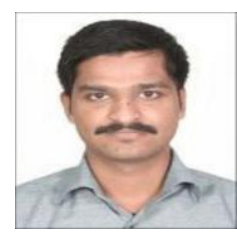

Industrial experience of piping engineering; currently working on design and CFD analysis of HATCT. 